\title{
Sciendo
}

Transport and Telecommunication, 2022, volume 23, no. 1, 81-92

Transport and Telecommunication Institute, Lomonosova 1, Riga, LV-1019, Latvia

DOI 10.2478/ttj-2022-0008

\section{COMPETENCE OF BUS RAPID TRANSIT SYSTEMS COUPLED WITH TRANSIT SIGNAL PRIORITY AT SIGNALIZED JUNCTIONS}

\author{
Robel Desta ${ }^{1}$, János Tóth ${ }^{2}$ \\ ${ }^{1,2}$ Department of Transport Technology and Economics, Faculty of Transportation Engineering and \\ Vehicle Engineering, Budapest University of Technology and Economics, \\ Muegyetem rkp. 3, 1111 Budapest, Hungary \\ Irobeldesta@edu.bme.hu, ${ }^{2}$ toth.janos@kjk.bme.hu
}

\begin{abstract}
One of the primary causes of poor public transport performance is delays at intersections. Among the efficient and sustainable solutions to boost mass transportation performance, Bus Rapid Transit (BRT) consists of infrastructures integrating dedicated bus lanes and smart operational service with different ITS technologies like Transit Signal Priority (TSP). This research studies the competence of buses operating on junctions of the BRT corridor where they have Signal Priority on the dedicated lane. The studied intersection is located around the center of the Addis Ababa BRT-B2 line, which is relatively gentle grade and characterized by the high traffic and pedestrian volume. Microscopic models were created for the chosen intersection, along with possible calibration and validation; moreover, a statistical comparison was performed to evaluate different scenarios with the goal of displaying the deployment benefits. To assess the performance of BRT buses and their overall influence on general traffic, scenarios with and without TSP were evaluated. PTV VISSIM and the VisVAP add-on simulation program were used to examine TSP alternatives. Incorporating TSP reduced the travel time by up to $4.78 \%$ in the priority direction, the average travel speed increased by $7.25 \%$, and the queue length also reduced by a maximum of $6 \%$, whereas in the non-priority direction, the queue length increased by a maximum of $2.5 \%$. Moreover, the overall average passenger delay has reduced by an average amount of $15 \%$. One of the simplest ways to improve transit performance could be signal priority strategies, which has a minor influence on the general traffic.
\end{abstract}

Keywords: Bus rapid transit, delay, ITS, PTV VISSIM, public transport performance, transit signal priority

\section{Introduction}

Metropolitan areas and highway networks in many cities around the world are experiencing rapidly increasing traffic congestion. Optimizing the performance of transportation infrastructure through various traffic management and operation strategies can reduce the impact of congestion. In carefully constructed experiments for a highway stretch with real demand situations, the effectiveness of the proposed mitigating methods is assessed. Furthermore, using microscopic simulation models and enhanced validation, the behaviour of the proposed experimental intervention schemes is analysed and appraised (Desta \& Tóth, 2021; Ziaei and Goharpour, 2019; Papadopoulou et al., 2017; Gunawan et al., 2014).

Bus Rapid Transit (BRT) is a cost-effective and long-term method for improving mass transit performance. It is a high-quality bus-based transportation system that provides dedicated lanes for buses, so it is considered fast, safe, comfortable and cheap. It necessitates infrastructure improvements such as BRT dedicated lanes, service integration, and operation with various intelligent transportation technologies such as Transit Signal Priority (TSP). Therefore, it is seen as an effective and inexpensive way to improve the reliability and efficiency of transit services (Prayogi and Satwikasari, 2019; Raj et al., 2013; Deng et al., 2013; Hensher and Golob, 2008).

TSP is a component of the Intelligent Transportation System (ITS) that modifies the normal signal operation process to better accommodate transit vehicles. It intends to minimize transit vehicle delay and travel time, thereby increasing the quality of a transit service; however, it should try to provide these benefits with as little impact on other road users as possible (Shaaban and Ghanim, 2018; Parr et al., 2014; Albright and Figliozzi, 2012). Different urban areas are executing BRT to make public transportation a more appealing travel option; however, it is preferable to develop virtual models in order to visualize the impact of TSP performance, which should be done prior to implementation on signalized intersections of BRT corridors. It assists in visualizing the real-world characteristics of traffic operational 
conditions. It also aids in visualizing traffic performance impacts under various conditions and scenarios, allowing decision makers to select the best approach during the deployment period (Prayogi and Satwikasari, 2019; Gunawan et al., 2014; Krajzewicz et al., 2012).

There are various micro-simulation software on the market that are used as tools for evaluating traffic management and control. PTV VISSIM (Planung Transport Verkehr - Verkehr In Städten SIMulations model), which was released in 1992, is a microscopic, time step, and behavior-based simulation model designed to model urban traffic and public transit operations. It can be used to analyze various traffic and transit operations under various conditions, as well as to aid in the assessment of traffic impacts of physical and operational alternatives in transportation planning. For its complexity and versatility, VISSIM can be considered a very technical software to work with. The simulation tool's applications include functions for testing TSP timing alternatives (Desta et al., 2021a; Papageorgiou et al., 2006; Smith et al., 2005; Ngan et al., 2004; Park and Schneeberger, 2003).

TSP and other operational measures may have an impact on overall traffic in both positive and negative ways. In general, TSP allows public transportation vehicles to pass through a congested signalized intersection more easily. However, due to various operational and technical problems, the efficiency of this technology may be highly distorted, and in order to deal with this, the responsible authority must assess its effectiveness on a regular basis. It is always crucial to see the impact or the possible problem, which may be affecting the operation of transportation systems to meet the user's needs (Desta et al., 2021b; Shaaban and Ghanim, 2018; Deng et al., 2013; Ngan et al., 2004). Since such infrastructure could be costly and may cause impedance to the general traffic, investigations should be conducted to evaluate their possible impacts behind their expected benefits. This study offers a unique perspective in this regard because it focuses on the evaluation of transit performance at signalized intersections along the BRT corridor using the developed microsimulation models, as well as the possible calibration and validation.

\section{Literature review}

Despite increased congestion, TSP can be an effective method of improving transit service, efficiency, and reliability. However, unless and until the results of this method are measured and evaluated, the system will never provide its full potential benefit. TSP's ultimate goal is to improve transit performance; however, understanding how TSP affects system performance is required to maximize the benefit of such measures, from local routes to BRT. The primary aspects of transit service that are exaggerated by TSP include travel time, speed, and reliability. Average speed, statistical variability in travel time, percentage of buses arriving on time, and frequency/variance of headway are four primary performance measures that can be used to determine travel speed and reliability (Shaaban and Ghanim, 2018; Zlatkovic et al., 2012; Smith et al., 2005).

TSP technologies can be used to extend or advance green times, or to allow left turn swaps, allowing buses that are running late to catch up, improving schedule adherence, reliability, and speed. The technology necessitates traffic signal controllers with embedded software, TSP capable equipment on the transit vehicle, and intersection equipment for identifying the transit vehicle and generating low priority requests when necessary (Albright and Figliozzi, 2012; Chen et al., 2008; Ngan et al., 2004; Baker et al., 2002). If a transit vehicle is approaching, the TSP strategy is used to extend the green interval by up to a predetermined maximum value. Detectors are strategically placed so that any transit vehicle that just misses the green light (by no more than the specified maximum green extension time) receives extended green time and is able to clear the intersection instead of waiting through an entire red interval (Al-Deek et al., 2017; Parr et al., 2014; Smith et al., 2005).

Green Extension benefits only a small percentage of buses (only delayed buses arriving during a short time window), but the reduction in delay for those buses that do benefit is significant (an entire red interval). This strategy is used to shorten the conflicting phases whenever a bus arrives at a red light in order to return to the bus's phase sooner. Conflicting phases are not terminated immediately, as is the case with emergency vehicle preemption systems, but are shortened by a predetermined amount. Early green benefits a large number of buses (any bus that arrives at a red light), but provides only a minor benefit to those buses. To increase the average benefits for transit, early green can be combined with green extension at the same intersection (Shaaban and Ghanim, 2018; Wolput et al., 2015; Parr et al., 2014; Albright and Figliozzi, 2012; Dion et al., 2004; Baker et al., 2002).

VisVAP (VISual Vehicle Actuated Programming) is a PTV VISSIM optional add-on module that simulates programmable phase or stage-based traffic actuated signal program controls. A simple 
programming language is used to describe the control logic in a text file. VisVAP interprets control logic commands and generates signal control commands for the VISSIM network during VISSIM simulation runs or in text mode. Various detector variables reflecting the current traffic situation are retrieved from the simulation and processed in the logic at the same time. Various studies in signal priority logic revealed that early green, extended green, and red truncation of TSP strategies are the most commonly used approaches (Smith et al., 2005; Dion et al., 2004; Ngan et al., 2004; Baker et al., 2002).

\section{Case study and methods}

The project of the BRT network line B2 (Figure 1) was considered in this study, which is developing along an axis crossing Addis Abeba city from north to south. The entire B2 BRT line stretches nearly $20 \mathrm{~km}$. The standard cross-section has two central lane bus ways with $3.5 \mathrm{~m}$ lane widths in each direction, with passing lanes of $3.5 \mathrm{~m}$ width on the adjacent sides for general traffic. For works related to both the BRT corridor and mixed traffic, the converted cross-section was between 25-40 meters wide along the corridor.

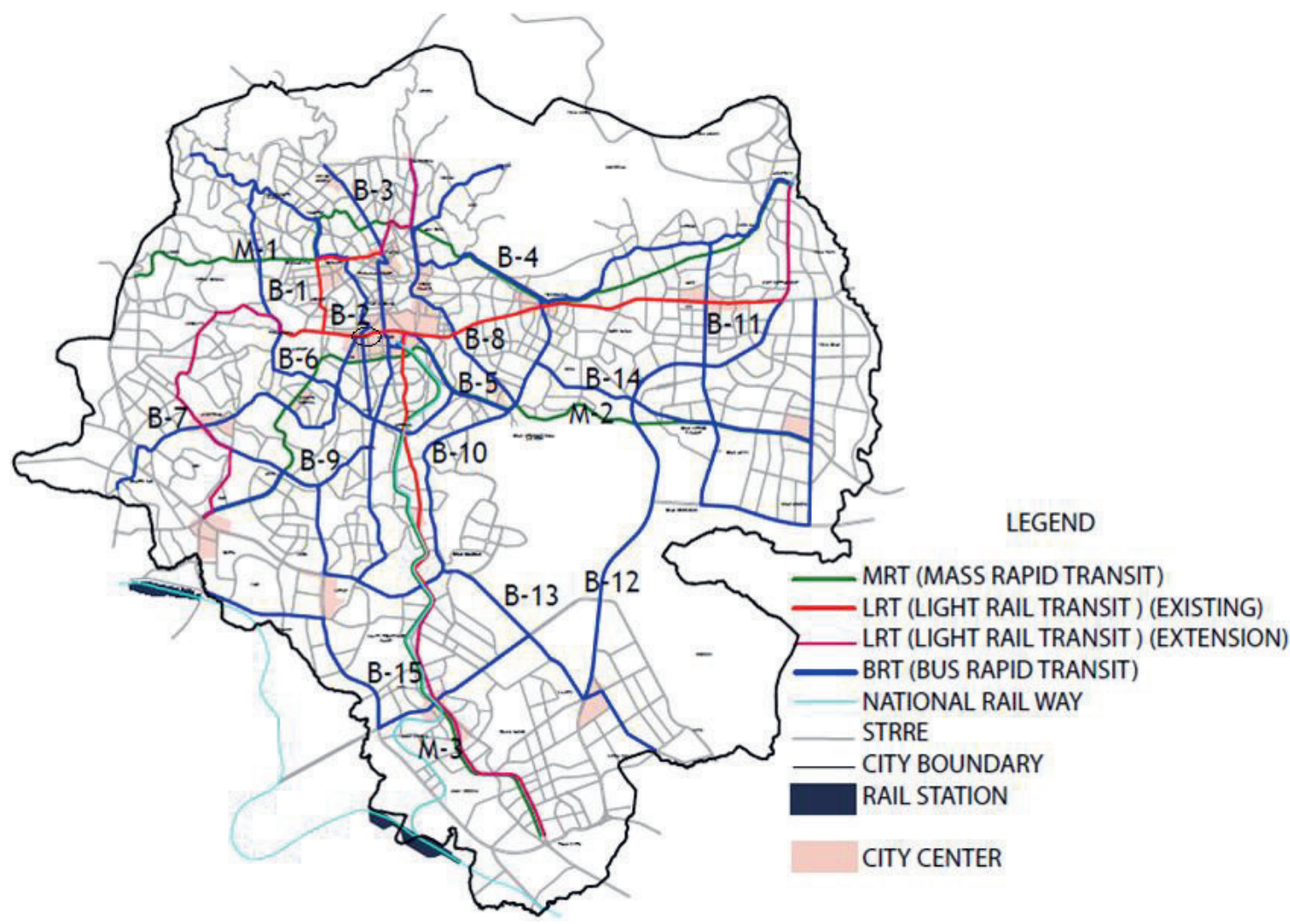

Figure 1. The proposed BRT corridor (B2 line) in Addis Ababa city (Source: (LTPA, 2010))

The purpose of this study is to describe the relationship and impact on traffic performance of the BRT-B2 operation at a specific intersection (Mexico square signalized intersection), which is being considered for TSP study (Figure 2). The intersection is located around the center of the BRT-B2 line, which is relatively gentle grade and characterized by the high traffic and pedestrian volume. For VISSIM, real time field data on classified intersection volume by vehicle type on each leg were collected for the development of the simulation models, including: road composition, categorized average vehicle sizes, mid-block traffic volume, spot speed and traffic observation data.

Furthermore, additional data were collected from the field for vehicle samples based on standard literature. Such data include actual vehicle categorized travel time (Garber and Hoel, 2008), time headways (Shawn et al., 1998), categorized total traffic delays (Garber and Hoel, 2008; Bhavsar et al., 2007), queue lengths (Shawn et al., 1998) and speed data (Garber and Hoel, 2008; Currin, 2001) to verify the validity of the simulation results with the actual traffic conditions. In developing the simulation models, the summary data acquired based on the above sampling procedures were therefore used. 


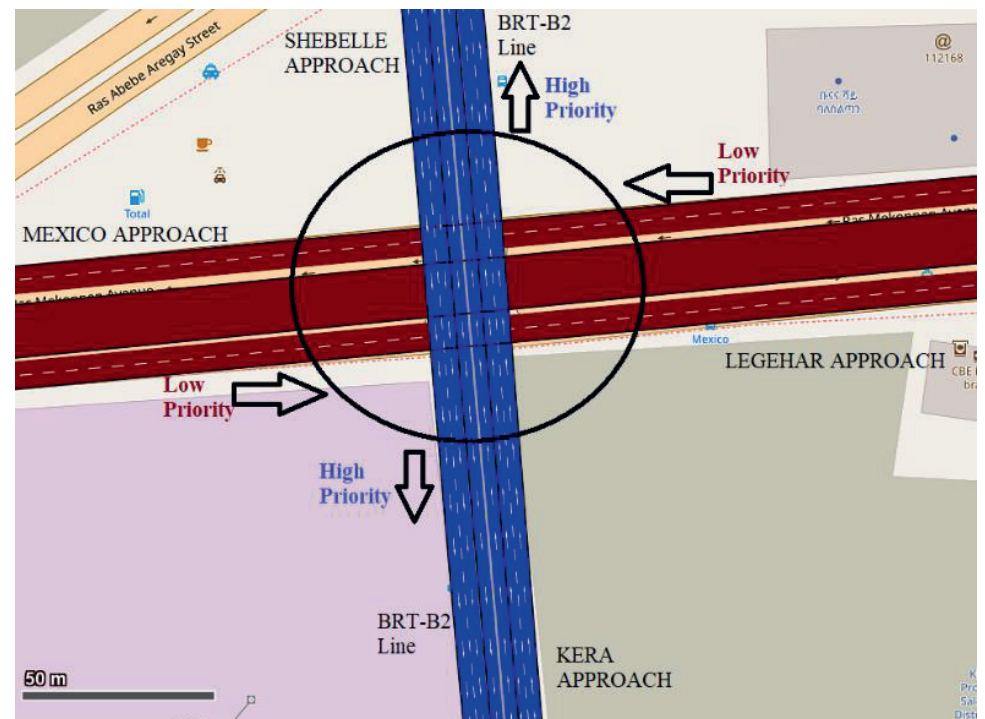

Figure 2. BRT direction at Mexico square signalized intersection near Ras Mekonen Avenue on the open street map

The Mexico square signalized intersection is the junction where the BRT is given priority and is expected to pass through the intersection with little impact on ordinary traffic. The BRT path is north to south, and it will have signal precedence over ordinary traffic traveling east to west (Figure 2).

At the intersection, basic measurements are acquired, which serve as preliminary geometric data for the VISSIM model. The number of lanes, lane width, lane arrangement, and grade of road, circulation width, entrance width, and median width are among the geometric features collected at intersections (Table 1).

Table 1. Mexico square signalized intersection basic geometry

\begin{tabular}{ccccc}
\hline $\begin{array}{c}\text { Mexico square signalized } \\
\text { Junction }\end{array}$ & $\begin{array}{c}\text { Shebelle } \\
\text { Approach }\end{array}$ & $\begin{array}{c}\text { Legehar } \\
\text { Approach }\end{array}$ & $\begin{array}{c}\text { Kera } \\
\text { Approach }\end{array}$ & $\begin{array}{c}\text { Mexico } \\
\text { Approach }\end{array}$ \\
\hline Number of entry lanes & 2 & 2 & 2 & 2 \\
Number of exit lanes & 2 & 2 & 2 & 2 \\
Width of entry lane (m) & 3.5 & 3.5 & 3.5 & 3.5 \\
Width of exit lane (m) & 3.5 & 3.5 & 3.5 & 3.5 \\
Width of BRT corridor & 3.5 & - & 3.5 & - \\
Width of separated island (m) & - & 10 & - & 10 \\
\hline
\end{tabular}

The study portrayed the existing vehicle traffic flow, road characteristics, travel time, traffic volume, and the traffic congestion in terms of delay, travel speed, queue length and travel time. Moreover, the paper described the relationship and impacts of traffic parameters along the route of BRTB2. Video camera on the marked streets and buildings were set to record the traffic activity for manual traffic count per 15-minute interval. The categorized directional traffic counts were then used to determine vehicular composition, vehicle occupancy rates and classifications of vehicles on the selected routes.

Traffic volume studies are conducted to determine the number, movements and classifications of roadway vehicles at the selected locations. For the input data in VISSIM, traffic volume has been counted considering different type of vehicles and movement directions. The traffic volume count was made for 12 hours starting from the morning 7:30 AM to the evening 7:30 PM at 15 minutes interval. The vehicles were counted in categories of cars and taxi, $4 \mathrm{WD}$, minibus taxi, mid-bus and standard bus, light, medium, heavy and articulated commercial or truck vehicles. However, pedestrian simulation in VISWALK is not incorporated in this study.

On the other hand, using the stop watch method, the spot speed study was completed on each approach of the intersection in order to determine the speed distribution at the intersection, and to validate the VISSIM model. The speed study was conducted using conveniently mounted high-resolution cameras and a stop watch for the better accuracy. According to Currin (2001), the study length determination on each intersection leg was made based on the speed range category of the approaching lanes. 
To establish the distribution along the intersection, an intersection volume and spot speed study was undertaken on each approach (Figure 3). Furthermore, the speed data are utilized to calibrate the PTV VISSM model, ensuring that the field circumstances are accurately represented.

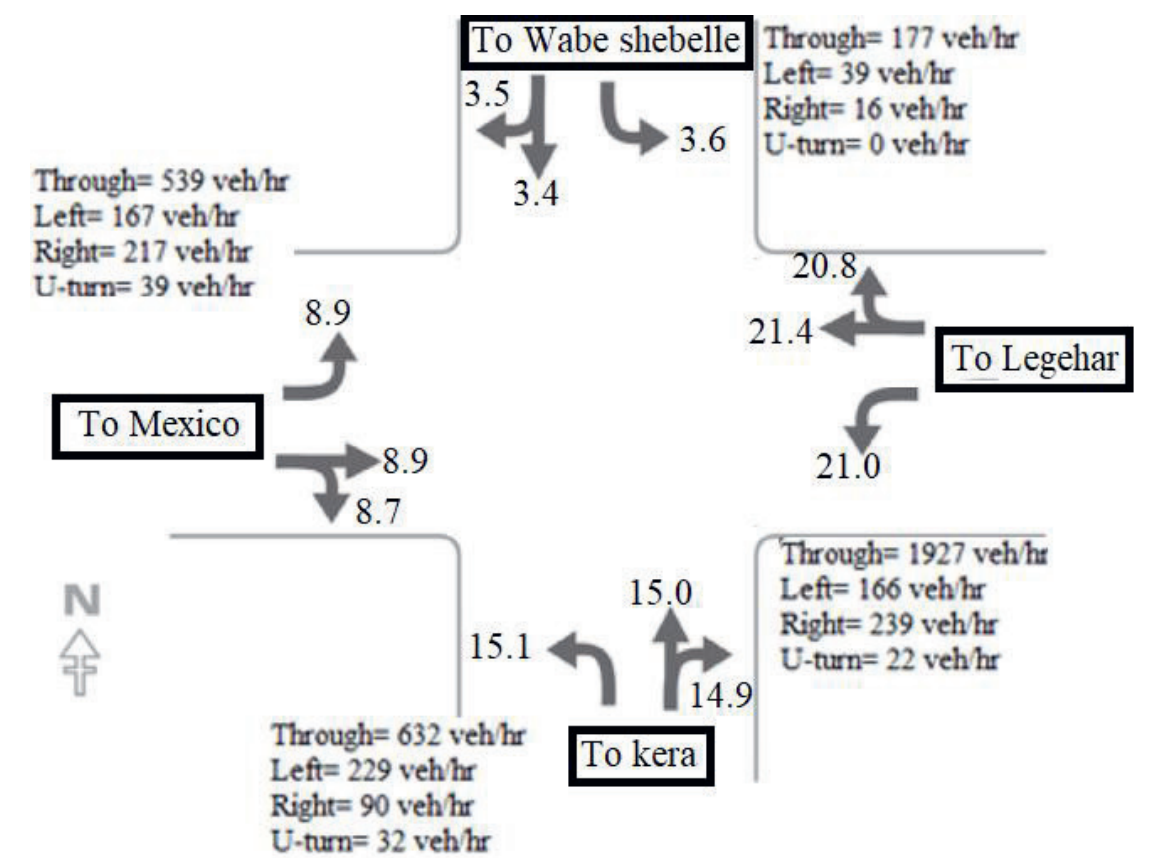

Figure 3. Total hourly volume on each approach and average travel speed including all delay effects $(\mathrm{km} / \mathrm{h})$

The fixed time signal cycle lengths data at Mexico square signalized intersection for the four phases were recorded for creating the signal program in VISSIM (Table 2), which facilitates the creation of a realistic base model. Accordingly, the existing signal phase pattern and timing at the intersection were gathered to build the signal program in VISSIM.

Table 2. Fixed time signal cycle lengths at Buna-Shay intersection

\begin{tabular}{ccccc}
\hline Signal Phase & $\begin{array}{c}\text { Shebelle } \\
\text { Approach }\end{array}$ & $\begin{array}{c}\text { Legehar } \\
\text { Approach }\end{array}$ & $\begin{array}{c}\text { Kera } \\
\text { Approach }\end{array}$ & $\begin{array}{c}\text { Mexico } \\
\text { Approach }\end{array}$ \\
\hline Green (sec) & 11 & 82 & 40 & 40 \\
Yellow (sec) & 3 & 3 & 3 & 3 \\
Red (sec) & 171 & 100 & 142 & 142 \\
$\begin{array}{c}\text { Total Cycle time of } \\
\text { the intersection (sec) }\end{array}$ & & \multicolumn{2}{c}{185} & \\
\hline
\end{tabular}

\subsection{Developing the base micro simulation model}

As stated in LTPA (2010), the proposed BRT B2 works with a virtual loop detector installed on the bus lane. At the point when a bus shows up in the virtual loop, it distinguishes the bus appearance and conveys a message to the traffic light regulator at the intersection. To prioritize the transit operation, the controller will initiate the bus priority signal cycle, which will reduce the green signal time for other arms of the junction or extend the green signal time for the bus lane. In the BRT B2 corridor, Green Extension of a buffer time less than or equal to $10-25 \mathrm{sec}$ is considered, whereas Red Truncation /Early Green/ of termination less than or equal to $10-25 \mathrm{sec}$ is considered. In this study, the fixed green extension and the early green time are both set to 15 seconds.

A scaled background map of the intersection along the BRT dedicated lane ensures accurate geometric representation when developing the model with PTV VISSIM. VISSIM was used to model the selected Mexico square signalized intersection using data obtained from the field (geometric data such as lane width, approach length, segregated lane, and section of the BRT-B2 corridor) and secondary data sources. The PTV VISSIM model (Figure 4) was validated using speed data from the field as well as data from the software output with justified confidence intervals. Following that, the TSP setups were evaluated at the intersection. 


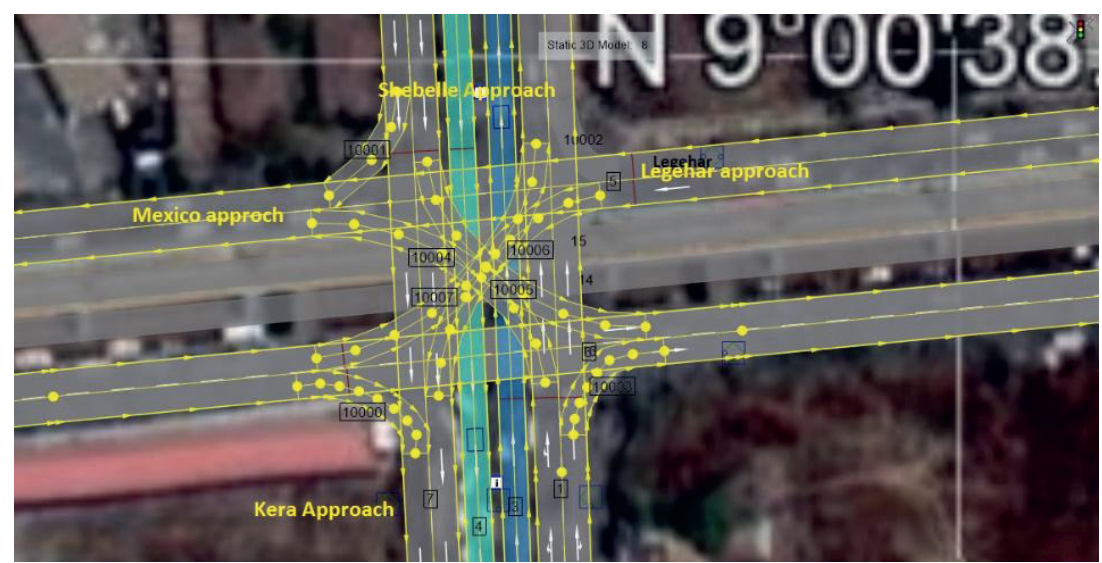

Figure 4. Snapshot of simulation model with the links, splined connectors, and reduced speed areas at Mexico square signalized intersection

Overall, PTV VISSIM annex software (VisVAP) was used in the model development to program the actuated signal controller. Scenario 1 will have No Green Extension / No Early Green, with the existing fixed cycle time remaining unchanged. Scenario 2's program consists of a 15-second green extension, a 15-second early green time, and a 15-second interruption of cycle time based on the call from the BRT buses reaching the detectors.

\subsection{Routing decision and vehicle attributes}

The general routing of BRT buses was made by combining inputs of vehicle attributes, vehicle route per direction, speed distribution, and inputs of public transport characteristics for the BRT. Vehicle routes were defined (static vehicle route decision) based on actual field conditions, taking the direction of the link flows into account (Figure 5). Then, for each movement type of the intersection, link relative flows were entered in each direction. Each routing decision displays the branches of possible movements as well as the relative flows/traffic volumes associated with them. The intersection's directional traffic flow was assigned in VISSIM, along with the relative flow of vehicles and vehicle types; each volume input was later calibrated for a higher level of accuracy in the model. Before inserting the relative vehicle volumes at each leg, new vehicle compositions were defined to represent the actual vehicle types in the corridor for those vehicle types that do not exist by default in VISSIM.

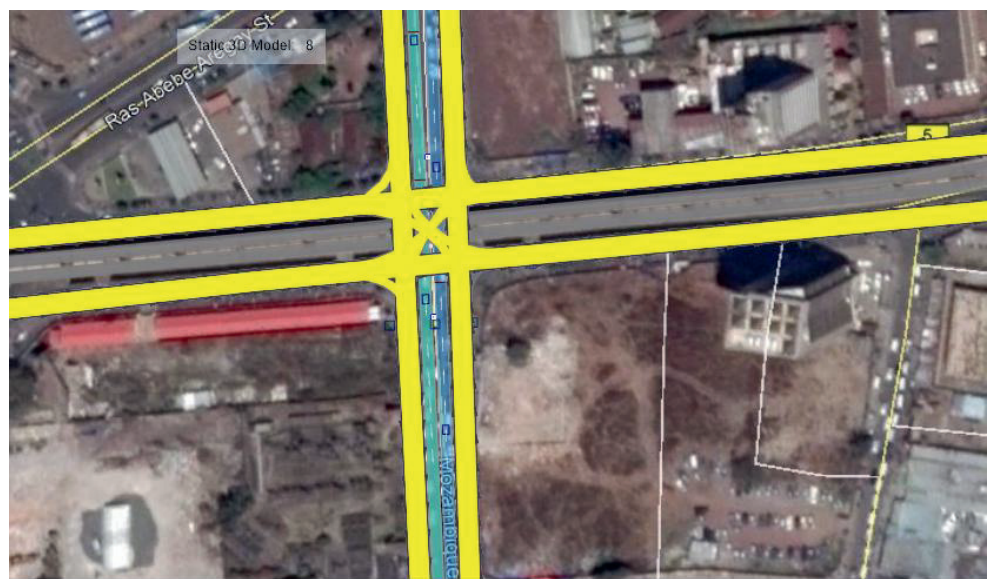

Figure 5. Snapshot of simulation model with the vehicle routes at Mexico square signalized intersection

\subsection{Signal controller}

A detector was installed near the signalized intersection on the BRT dedicated lane (Figure 6). The intersection's signal control was based on the existing signal scheme and priority given via the sensor, which is initiated by a call from BRT buses approaching an intersection. By interrupting the fixed signal cycle, the system was able to incorporate an optimal green extension and red truncation. 
The main component of this study is modeling traffic signal control to simulate the 'before' case and deploying a 'green extension/early green' priority logic to investigate the 'after' case. As a result, it was critical to outperform the signal control data and program the model for deploying the priority strategy. In this study, a VisVAP-based approach was used to model selected intersections signal programs in VISSIM, which include various signal head groups attributed to different lane geometric configurations.

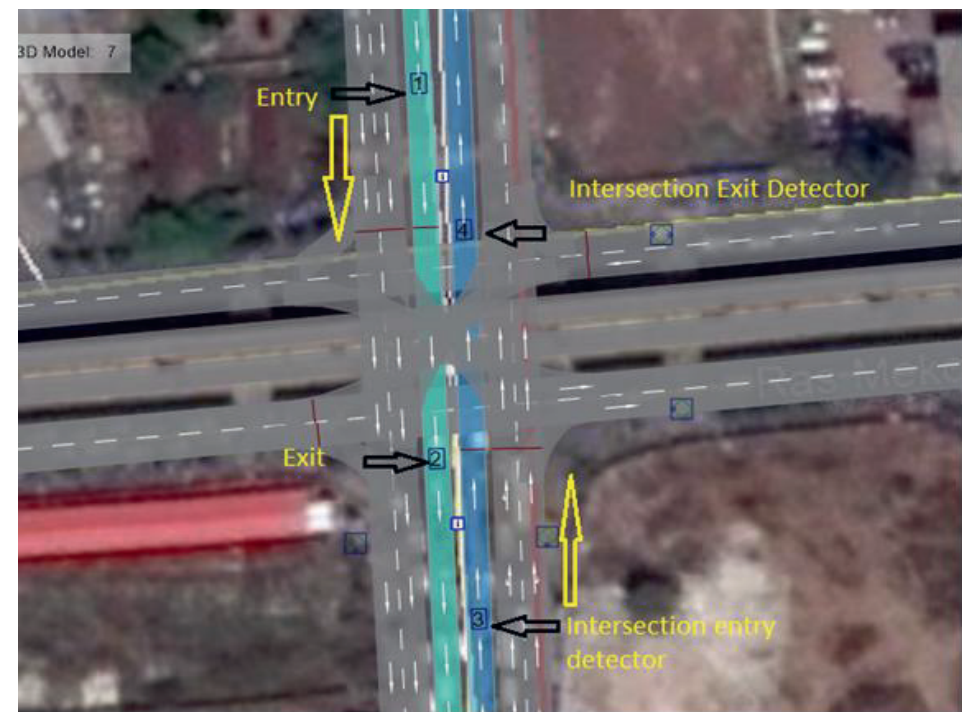

Figure 6. Signal and detector coordination in VISSIM

One of the most important aspects of this research was ensuring that traffic signal operations were disrupted as little as possible. This feature was especially important at the chosen study junction, where the main corridor is a major urban road with high traffic volumes during peak hours; additionally, the deployment is planned for green extension. As a result, the study included a 15 -second green extension and a 15 -second red truncation to assess the potential outcomes of the strategies.

\subsection{Validation of the model}

The validation and calibration of the model is an important process in the simulation process because it provides credibility to the results by closely representing the actual conditions. Calibration entails adjusting the default values of the PTV VISSIM software, which may not be representative of the driving and geometric characteristics of the study segment. The validation process entails comparing and justifying the results (field and VISSIM output) with the level of accuracy provided by confidence intervals (Raj et al., 2013; Vedagiri \& Jain, 2012; Park and Schneeberger, 2003). Typical calibration measures include taking into account traffic parameters such as volume, delay, and travel speeds.

The model calibration in this paper involves adjustment of different vehicle and driver behaviours in VISSIM based on parametric field data in the study area. In the vehicle behaviours, for each vehicle type, the desired speed distribution and acceleration-deceleration behaviours were adjusted. For the driver's behaviours, the adjusted parameters include the driving behaviour when following other cars, the adopted Wiedemann 74 car following model parameters for each vehicle category, the lane change behaviours, lateral distance (desired position at free flow, overtaking behaviours, diamond queueing etc.), drivers' behaviours at signal control, autonomous driving parameters and drivers' errors.

The GEH formula, as given in Equation (1), is considered to be the best universal metric for comparing field data with simulation results (Desta et al., 2021a; Papageorgiou et al., 2015; WSDOT, 2014).

For hourly throughput volumes, the GEH formula is:

$G \boldsymbol{E} H=\sqrt{\frac{2(m-c)^{2}}{m+c}}$.

Where,

$\mathrm{m}=$ output traffic throughput volume from the simulation model (veh/h),

$\mathrm{c}=$ traffic throughput volume based on field data $(\mathrm{veh} / \mathrm{h})$. 
Since the throughput volume from the output simulation model and the field data are found to be $3236 \mathrm{veh} / \mathrm{h}$ and $3275 \mathrm{veh} / \mathrm{h}$ respectively. According to the guidance formulated on interpreting the calculated GEH statistic for throughput traffic volume calibration criteria, a value of 3 or lower for high strength and a value above 5 is unacceptable (Desta et al., 2021a; WSDOT, 2014). Hence, the GEH statistics is around 0.47 , which is well below the upper limit for low strength threshold.

In this study, average operating speed (spot speed) was used as a measure of transit network effectiveness. Vehicles' average spot speed within the speed distribution ranges from 5 to $55 \mathrm{~km} / \mathrm{h}$. During the simulation process, VISSIM allows the operating speed of a class of vehicles to be controlled. The average operating speed ranged from 5 to $60 \mathrm{~km} / \mathrm{h}$, which corresponded closely to the field data. Furthermore, the signal time distributions observed from the VISSIM output for the 'No TSP' case are similar to the inputs from field conditions, providing additional support for signal control. With a 95\% confidence level, the speed distributions in VISSIM and in the field compare favourably (Figure 7). As a result, the model is closely related to the real traffic behaviour in the field.

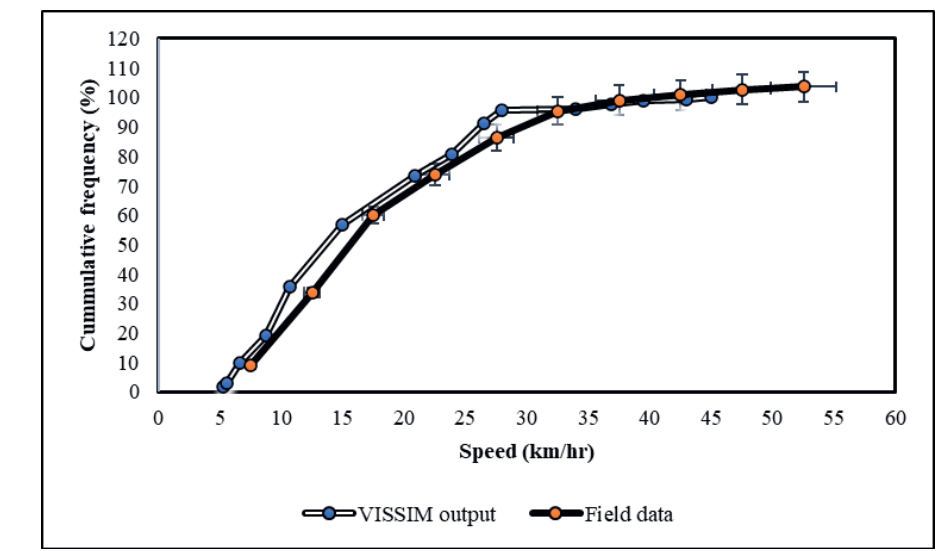

Figure 7. Comparison of speed distribution from PTV VISSIM with field measurement

\subsection{Simulated signal scenarios and scenario management}

In simulation runs, two scenario groupings were implemented, which can be distinguished by certain characteristics being simulated. A total of 25 simulation runs were made for each scenario considering a network warm-up period of $300 \mathrm{sec}$, data collection period of $3600 \mathrm{sec}$ and network warmoff period of $300 \mathrm{sec}$. The two scenarios studied were No Transit Signal Priority (scenario I) and Transit Signal Priority (scenario II) (scenario II). The difference in signal phase coordination between the two scenarios resulted in significant changes in transit operation performance (Figure 8).

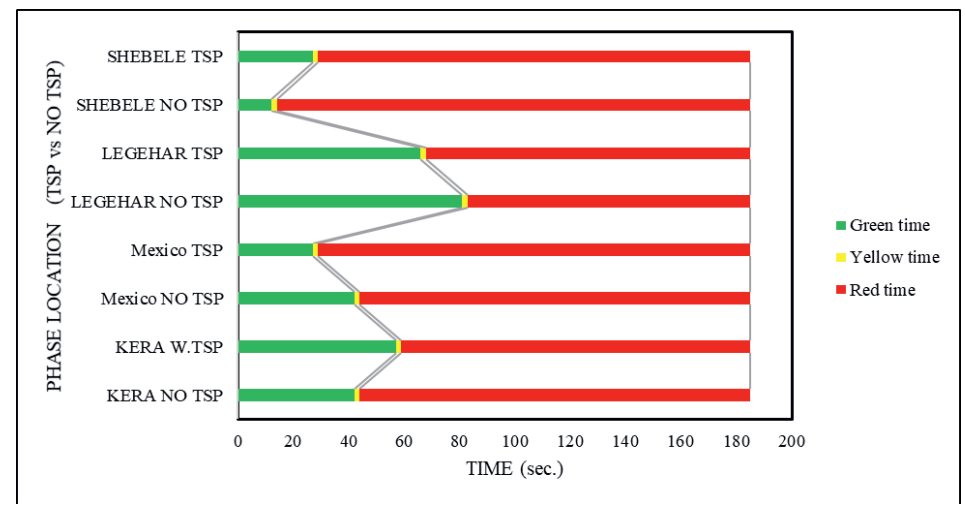

Figure 8. Green Extension and early Green on intersection phase in the two scenarios

Scenario management was used during the simulation to facilitate the assessment of traffic parameters in order to investigate the impact of signal priority on the performance of BRT B2 buses and general traffic. As a basic TSP plan and method of detecting the bus arrival at an intersection, green extension of 15 seconds (GE-15), and red truncation / early green 15 seconds (EG-15), are critical dimensions in the scenarios. In general, the simulation network can fuse 15-20 seconds of GE and EG 
extension. The above signal modification of green extension and early green was applied to the existing signal in order to experiment with the variations that occur. VisVAP logic, which is used to program the detector call, was used to make changes to the signal coordination.

\section{Results and Discussions}

The extracted average output data for the 25 simulation runs in each scenario from PTV VISSIM result directory include travel time, delay, and queue length of BRT buses, and the general traffic. For the assigned approach crossing segment at the intersection (North to South), the vehicles travel time were extracted from VISSM output directory for both scenarios (Figure 9). The travel time of the BRT North to South line has been significantly reduced by an average of 2.83 percent.

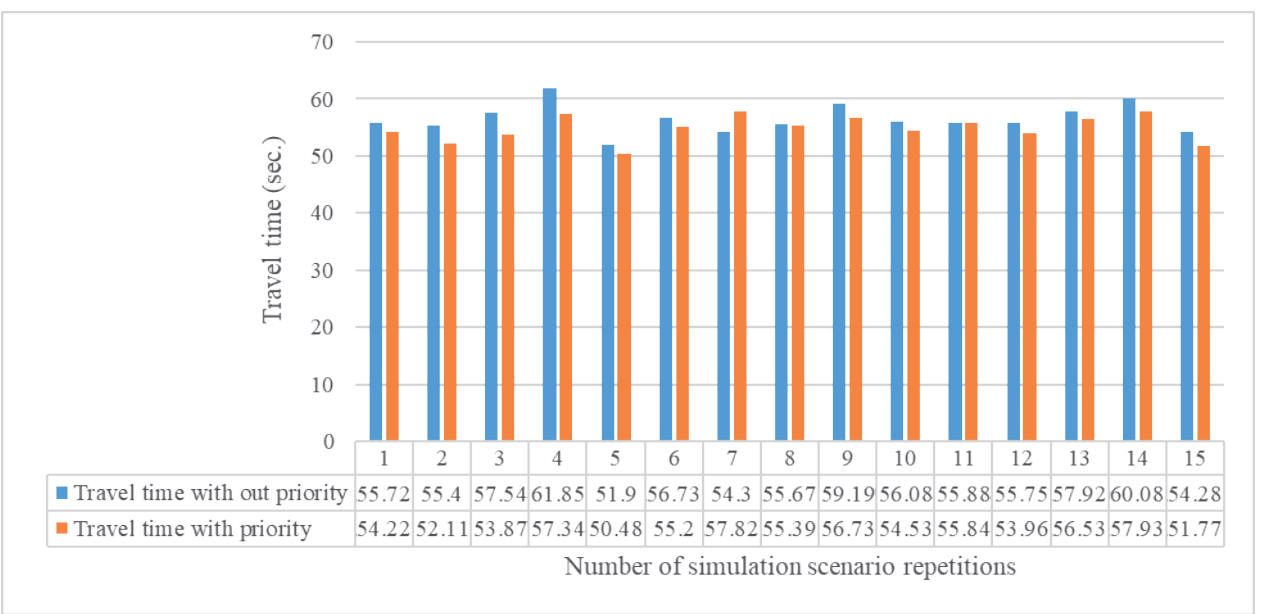

Figure 9. Travel time of BRT vehicles from North bound Shebelle approach to South bound Kera approach

Data extracted for the South to North flow revealed a significant improvement in BRT travel time, with an average 4.78 percent decrease in overall travel time (Figure 10).

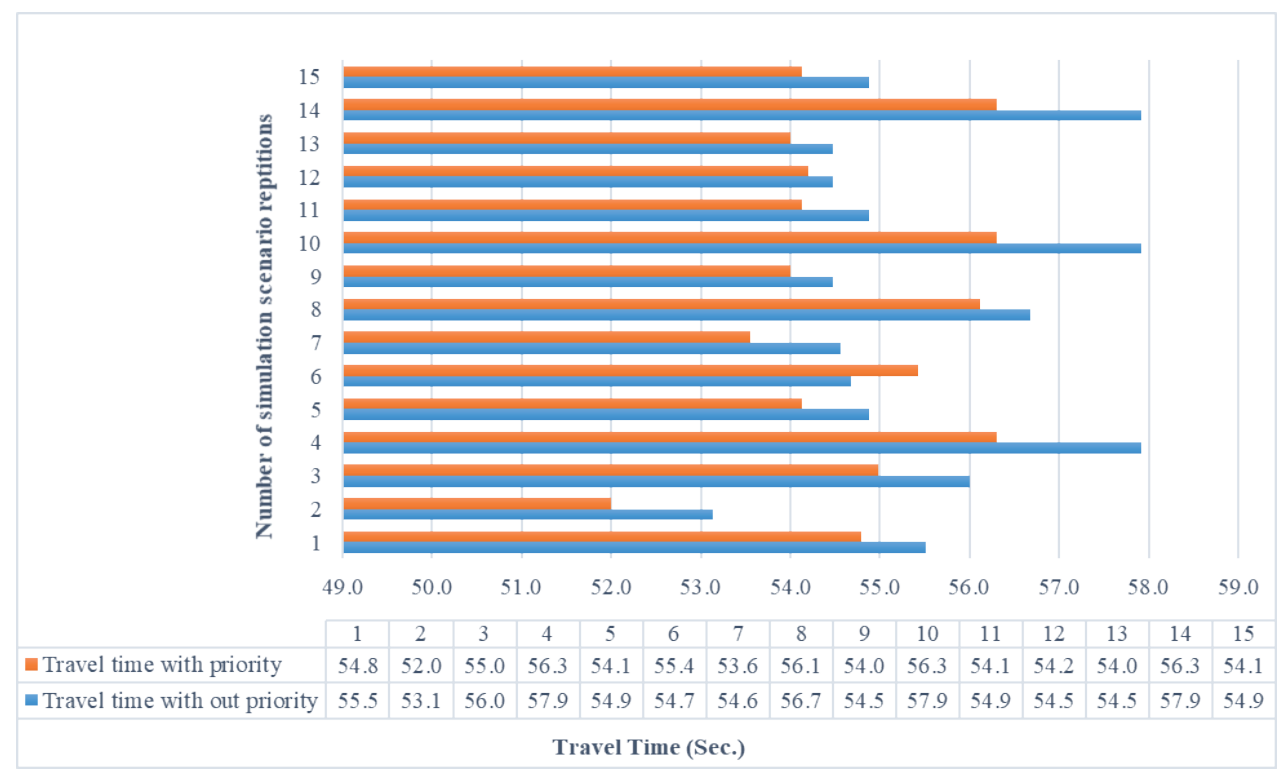

Figure 10. Travel time of BRT vehicles from South bound Kera approach to North bound Shebelle approach

The average queue length of the simulation results from the VISSIM results directory were summarized for average values based on vehicle composition and general traffic category (Table 3 ). The priority direction in Kera and Shebelle has reduced queue length by $1.5 \%-5.9 \%$, whereas the non-priority side of the intersection increase queue length by $1.1 \%-2.5 \%$. 
Table 3. Summary of average queue length at the different approaches of the intersection

\begin{tabular}{ccccc}
\hline Queue Length & $\begin{array}{c}\text { Shebelle } \\
\text { Approach }\end{array}$ & $\begin{array}{c}\text { Legehar } \\
\text { Approach }\end{array}$ & $\begin{array}{c}\text { Kera } \\
\text { Approach }\end{array}$ & $\begin{array}{c}\text { Mexico } \\
\text { Approach }\end{array}$ \\
\hline Queue length before TSP (meter) & 11.8 & 52.2 & 32.8 & 28.3 \\
Queue length after TSP (meter) & 11.1 & 53.5 & 32.3 & 28.6 \\
Difference (meter) & -0.7 & 1.3 & -0.5 & 0.3 \\
Percentage change (\%) & -5.9 & 2.5 & -1.5 & 1.1 \\
\hline
\end{tabular}

According to the PTV VISSIM simulation results, the selected BRT corridor's travel speed increased by an average of $7.25 \%$. The Speed variability for BRT vehicles with and without transit signal priority was significant (Figure 11).

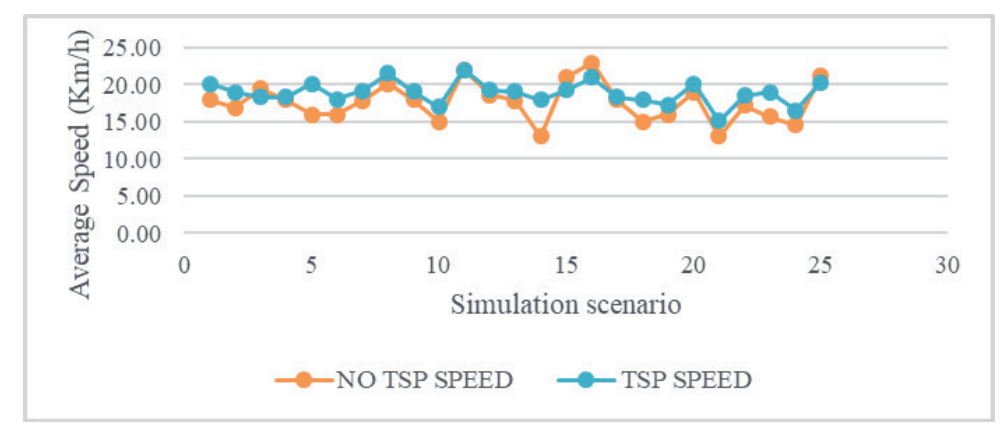

Figure 11. Speed variability of BRT Vehicles for No TSP and with TSP conditions

The average passenger delay for the multiple simulation cases indicated a positive result, which is an average of $10 \%-20 \%$ delay reduction in comparison to the no priority case, based on the overall results of the simulation scenarios (Figure 12).

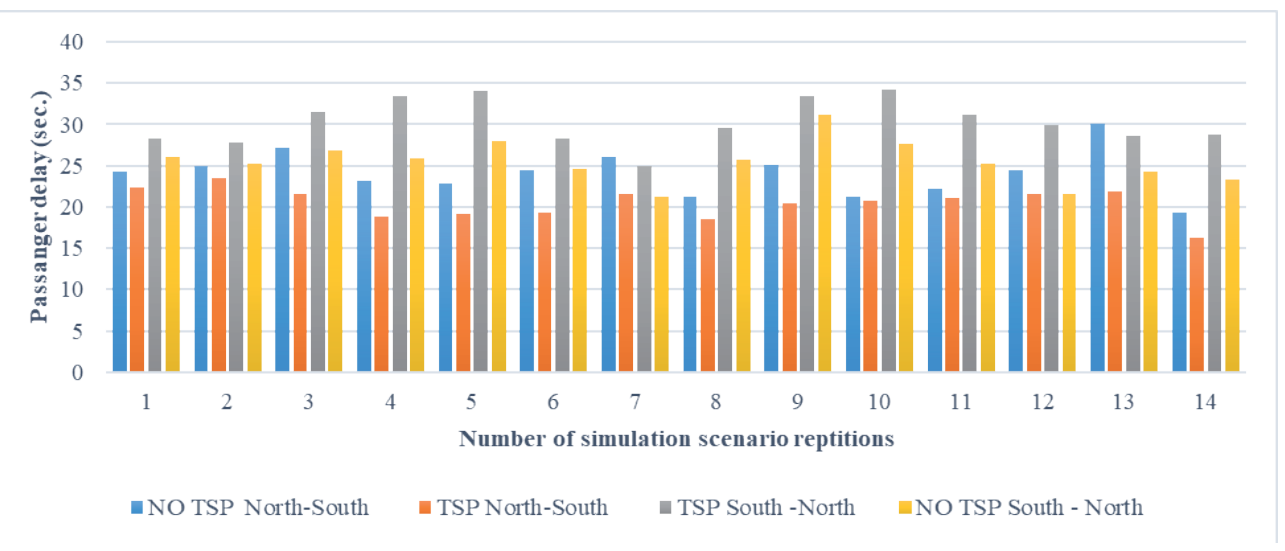

Figure 12. Average Delay of BRT vehicle passengers in the No TSP and With TSP scenarios

\section{Conclusions}

This research contributed to the development of a simulation model with a relative evaluation of several scenarios for testing transit signal priority approaches at BRT route crossings. The study focused on the performance of buses that travel in a separate lane and are given signal priority at intersections over other traffic. In addition, the impact on overall traffic performance was investigated in order to assess the pre- and post-deployment circumstances of transit signal priority on BRT lanes.

According to the results of the experimental investigations, the PTV VISSIM simulation output, and statistical comparisons, the TSP significantly improves the performance of BRT buses at an intersection level crossing. Furthermore, the implementation of TSP resulted in a minimum of a $4 \%$ reduction in average journey time for BRT buses. The average reduction in BRT line passenger delays was found to be $10-20 \%$, while the travel speed of BRT vehicles was enhanced by $7-8 \%$. TSP may lower 
the general traffic queue length by roughly $2 \%$ in the priority direction (parallel to the BRT lane), while the queue may increase by up to $3 \%$ in the non-priority direction.

In general, TSP implementation have little impact on the traffic performance of the general traffic, while it can prompt extensive functional improvement for vehicles in the BRT path. Moreover, the consideration of eco-friendly buses with zero emission like battery-electric buses could substantially ensure the overall sustainability in all perspectives.

\section{Data availability}

All data, models, or code generated or used during the study are available upon request from the corresponding author.

\section{Acknowledgement}

The authors would like to thank all of the professionals who contributed to this work, particularly the Transportation Programs Management Office (TPMO), Traffic Safety and Management (TSM) division staffs, and BRT unit staffs, for their technical assistance. The authors would like to express their heartfelt gratitude to the Ethiopian Roads Authority (ERA) and Hawassa University for funding this research.

\section{Conflict of interest}

The authors declare that they have no competing interest.

\section{References}

1. Al-Deek, H., Sandt, A., Alomari, A., Hussain, O. (2017) A technical note on evaluating the effectiveness of bus rapid transit with transit signal priority. Journal of Intelligent Transportation Systems, 21(3), 227-238.

2. Albright, E. and Figliozzi, M. (2012) Factors influencing effectiveness of transit signal priority and latebus recovery at signalized-intersection level. Transportation Research Record, 2311(1), 186-194.

3. Baker, R.J., Collura, J., Dale, J.J., Head, L., Hemily, B., Ivanovic, M., Jarzab, J.T., McCormick, D., Obenberger, J., Smith, L., Stoppenhagen, G.R. (2002) An Over-view of Transit Signal Priority, ITS America, Washington, D.C.

4. Bhavsar, J.N., Sharma, S., Dhingra, S.L. (2007) Simulating Bus Priority System for an Urban Corridor in Mumbai City. In: 11th World Conference on Transport Re-search. I.C.T. Pvt. Ltd., A-8 Green Park, New Delhi 110016. Civil Engineering Department, I.I.T., Powai, Mumbai 400076. India.

5. Chen, X., Yu, L., Zhu, L., Yu, L., Guo, J. (2008) Microscopic simulation approach to effectiveness analysis of transit signal priority for bus rapid transit: A case study in Beijing. Transportation Research Record, 2072(1), 64-76.

6. Currin, T.R. (2001) Spot Speed Study. Introduction to Traffic Engineering: A Manual for Data Collection and Analysis, ed. B. Stenquist. Stamford, Conn.: Wadsworth Group, 4-12.

7. Deng, T., and Nelson, J. D. (2013) Bus rapid transit implementation in Beijing: An evaluation of performance and impacts. Research in Transportation Economics, 39(1), 108-113.

8. Desta, R., Tesfaye, D., Tóth, T. (2021a) Microscopic Traffic Characterization of Light Rail Transit Systems at Level Crossings. In: Hindawi-Advances in Civil Engineering, 1-11.

9. Desta, R., Dubale, T., Tóth, T. (2021b) Transit Performance Evaluation at Signalized Intersections of Bus Rapid Transit Corridors. In: 7th International Conference on Vehicle Technology and Intelligent Transport Systems - VEHITS, 618-625.

10. Desta, R., Tóth, T. (2021) Simulating the performance of integrated bus priority setups with microscopic traffic mockup experiments. In: Elsevier- Journal Scientific African, 11, 1-11.

11. Dion, F., Rakha, H. and Zhang, Y. (2004) Evaluation of potential transit signal priority benefits along a fixed-time signalized arterial. Journal of Transportation Engineering, 130(3), 294-303.

12. Garber, N.J., Hoel, L.A. (2008) Traffic and Highway Engineering, 4th Ed., University of Virginia: United States of America, Cengage Learning, 99-140.

13. Gunawan, F.E., Suharjito, Gunawan, A.A.S. (2014) Simulation Model of Bus Rapid Transit. In: EPJ Web of Conferences. EDP Sciences, 21, 1-7. 
14. Hensher, D. A., Golob, T. F. (2008) Bus rapid transit systems: a comparative assessment. Transportation, 35(4), 501-518.

15. Krajzewicz, D., Erdmann, J., Behrisch, M., Bieker, L. (2012) Recent Development and Applications of SUMO - Simulation of Urban Mobility. In: International Journal on Advances in Systems and Measurements, 5(3\&4), 128-138.

16. Lyon Town Planning Agency-LTPA. (2010) Addis Ababa Bus Rapid Transit Line Feasibility study. Available at: https://docplayer.net/54352900-Feasibility-study-bus-rapid-transit-line-addis-ababa.html.

17. Ngan, V., Sayed, T., Abdelfatah, A. (2004) Impacts of Various Parameters on Transit Signal Priority Effectiveness. In: Journal of Public Transportation, 7(3), 71-93.

18. Papadopoulou, S., Papamichail, I., Roncoli, C., Bekiaris-Liberis, N., Papageorgiou, M. (2017) Microscopic simulation-based validation of a per-lane traffic state estimation scheme for highways with connected vehicles. In: Elsevier Transportation Research Part C, 86, 441-452.

19. Papageorgiou, G., Damianou, P., Pitsilides, A., Thrasos, A., Ioannou, P. (2006) A Microscopic Traffic Simulation Model for Transportation Planning in Cyprus. In: International Conference on Intelligent Systems and Computing: Theory and Ap-plications, 157-166.

20. Papageorgiou, G., Maimaris, A., Petros, I. (2015). Analysis and evaluation of intelligent bus rapid transit systems in Cyprus. In: 2015 IEEE 18th International Conference on Intelligent Transportation Systems, 95-100.

21. Park, B. and Schneeberger, J.D. (2003) Microscopic simulation model calibration and validation: case study of VISSIM simulation model for a coordinated actuated signal system. In: Transportation Research Record, 1856(1), 185-192.

22. Parr, S.A., Kaisar, E.I., Stevanovic, A. (2014) Application of Transit Signal Priority for No-Notice Urban Evacuation. In: ASCE Journal of Natural Hazards Review, 15(2), 167-170.

23. Prayogi, L., Satwikasari, A.F. (2019) Bus Rapid Transit-Oriented Development: An Identification of Bus Rapid Transit System Passengers' Modal Shift Potential Considerations. In: CSID Journal of Infrastructure Development, 2(1), 127-136.

24. Raj, G., Sekhar, C.R., Velmurugan, S. (2013) Micro simulation Based Performance Evaluation of Delhi Bus Rapid Transit Corridor. In: Elsevier Procedia - Social and Behavioral Sciences, 2nd Conference of Transportation Research Group of India (2nd CTRG), 104, 825-834.

25. Shaaban, K., Ghanim, M. (2018) Evaluation of Transit Signal Priority Implementation for Bus Transit along a Major Arterial Using Microsimulation. In: Elsevier Procedia Computer Science, The 9th International Conference on Ambient Systems, Networks and Technologies (ANT 2018), 130, 82-89.

26. Shawn, M.T., William, L.E., Robert, J.B., Douglas, J.H. (1998) Travel Time Data Collection Handbook: Texas Transport Institute. The Texas A\&M University System: Collage station, Texas 77843-3135, USA.

27. Smith, H.R., Hemily, B., Ivanovic, M. (2005) Transit Signal Priority (TSP): A Planning and Implementation Handbook. ITS America. US Department of Transportation, Washington DC.

28. Vedagiri, P., Jain, J. (2012) Simulating Performance Impacts of Bus Priority Measures. In: ACEE Int. J. on Transportation and Urban Development, 2(1), 15-19.

29. Wolput, B., Christofa, E., Carbonez, A., Skabardonis, A., Tampère, C.M.J. (2015) Optimal Traffic Signal Settings with Transit Signal Priority. In: Transportation Research Board 94th Annual Meeting Washington D.C.

30. WSDOT (2014) Washington State Department of Transportation (WSDOT): Protocol for VISSIM Simulation: VISSIM validation criteria.

31. Ziaei, M., Goharpour, A. (2019) Performance Evaluation of Tehran Bus Rapid Transport (BRT) Routes by the Two-stage Data Envelopment Analysis (DEA) Model. In: IJRRAS 38(1), 87-92.

32. Zlatkovic, M., Stevanovic, A., Martin, P. T., Tasic, I. (2012) Evaluation of transit signal priority options for future bus rapid transit line in West Valley City, Utah. Transportation research record, 2311(1), 176-185. 